\title{
Retained laser fiber cover sleeve following laser lipolysis
}

\author{
Uwe Wollina* \\ Department of Dermatology and Allergology, Academic Teaching Hospital Dresden-Friedrichstadt, Dresden, Germany
}

\begin{abstract}
Laser lipolysis is a minimally invasive procedure to reduce localized adipose tissue depots. We report a hitherto unknown possible adverse effect. A case of a 33-yearold female patient with residual lipedema of the medial parts of the knees was treated by laser lipolysis using a bare fiber without suction. She presented later with retains of the cover sleeve of the laser fiber, that had been removed after local incision. The loss of the cover sleeve was unnoticed during the procedure. Possible mechanisms of severance of cover sleeve are discussed. A practical consequence is the need of regular check of bare fibers after laser lipolysis.
\end{abstract}

\section{Introduction}

The combination of laser and liposuction has been initially investigated by Apfelberg [1]. Goldman et al. used a pulsed Nd-YAG $1064 \mathrm{~nm}$ laser and demonstrated versatility, efficacy and safety of these methods for lipoplasty [2]. Skin tightening is a major advantage of this combined technique. In addition, ecchymosis, edema, and postprocedural pain may be diminished $[3,4]$.

Lasers of various wavelength have been developed for laser-assisted lipoplasty, such as diode lasers $(924 \mathrm{~nm}, 940 \mathrm{~nm}, 968 \mathrm{~nm}, 980 \mathrm{~nm})$, Nd:YAG lasers (1064 nm, 1319 nm, $1320 \mathrm{~nm}, 1344 \mathrm{~nm}, 1440 \mathrm{~nm})$, or a combination of different wavelength and/ or lasers [5-7].

Further studies investigated the technique and compared laser lipolysis with and without suction. In a study with upper arm contouring, the authors rated both methods equally effective at six months [8]. The use of subdermal (interstitial) laser is an alternative for limited adiposis and not a substitute for liposuction of larger body areas.

Safety has been evaluated in $>500$ laser-assisted lipoplasty patients. The complication rate was $0.93 \%$ without systemic adverse effects. The most common side effect in this retrospective evaluation was skin burns. In addition, one local infection was observed [9].

Here we report an unusual complication of laser lipolysis of circumscribed adiposis.

\section{Case report}

A 33-year old female patient with lipedema of her legs had been treated with laser-assisted liposuction successfully (Figure 1). We used a $980 \mathrm{~nm}$ diode laser for lipoplasty in tumescent anesthesia as described elsewhere [7] and totally 4,450 $\mathrm{ml}$ lipoaspirate could be removed.

She presented for a touch-up of the medial juxta-articular parts of her knees. Since the remaining adiposis was mild and circumscribed, laser lipolysis without suction was performed.

Tumescent local anesthesia was infiltrated in the treatment area. Protective laser goggles were worn by the patient and the surgical staff. Skin was punctured with a $17 \mathrm{G}$ coaxial needle with trochar (Biopsy Bell Introduttore, $150 \mathrm{~mm}$ length; BPB Mirandola, Italy). After removal of the trochar, a $600 \mu \mathrm{m}$ bare fiber (Ceralas BBF 603 DL classic; CeramOptotec Bonn, Germany) was inserted through it. The coaxial needle served as guidance for the bare fiber. Laser energy was delivered by a $980 \mathrm{~nm}$ diode laser (Ceralas HPD, Biolitec, Jena, Germany). The laser was used in continuous mode with a power of $20 \mathrm{~W}$. Skin temperature was monitored by continuously touching the skin above the laser beam to avoid skin burns. The total energy delivered was $4,087 \mathrm{~J}$ for both knees. The patient tolerated the procedure very well and went home. The next day she got manual lymph drainage by a physiotherapist. During the procedure a foreign body was noted under her skin on the right side. Under local anesthesia and incision two $5 \mathrm{~cm}$ and $7 \mathrm{~cm}$ large pieces of plastics had to be removed from the treated area on the right site (Figure 2).

The material was analyzed and it could be identified as cover sleeve of the laser bare fiber without any bare fiber remnants. The loss of the protective coating was not noted during the procedure. The company

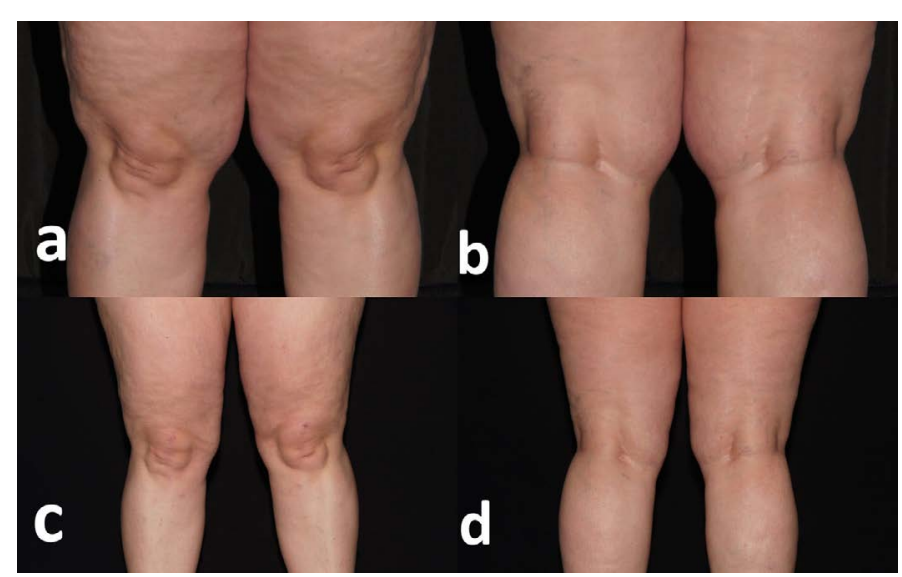

Figure 1. Knees before (a, b) and after (c, d) laser lipolysis.

Correspondence to: Prof. U Wollina, Department of Dermatology and Allergology, Academic Teaching Hospital Dresden-Friedrichstadt, Friedrichstrasse 41,01067 Dresden, Germany, E-mail: wollina-uw@khdf.de

Key words: laser lipolysis, bare fibers, lipedema, retained foreign body

Received: July 20, 2016; Accepted: August 15, 2016; Published: August 17, 2016 
was contacted and no other cases with a comparable device-related complication had been recorded. Ultrasound investigations of both treated area excluded any opaque remnants.

\section{Discussion}

Laser-assisted liposuction (lipoplasty) and laser-assisted lipolysis are established and generally safe procedures for body contouring and skin tightening $[2,3,5-8]$. The most common adverse effects reported are skin burns (Table 1). The risk of skin burns can be reduced with tumescent anesthesia, choosing appropriate laser parameters, monitoring skin temperature ( $<40$ degree Celsius), skill and experience $[5,9]$.

Fibers for laser lipolysis consist of two technical components: The fiber itself necessary for light transport and the protective cover. Both components may be involved in unwanted adverse events.

\section{Mechanisms of fiber damage}

Very rarely, retains of bare fibers have been reported during endovenous laser ablation caused mechanically or by laser light absorbed by the cover sleeve and converted into heat during bending stress [10-12]. These retains can be identified by ultrasound [12].

\section{Mechanisms for protective cover damage}

Holdstock et al. (2008) investigated ex vivo the possibility of laser fiber damage during tumescent anesthesia. They punctured a bare fiber with a $21 \mathrm{G}$ needle and observed thereafter light energy concentrated to the point of damage to the protective cover sleeve. This causes

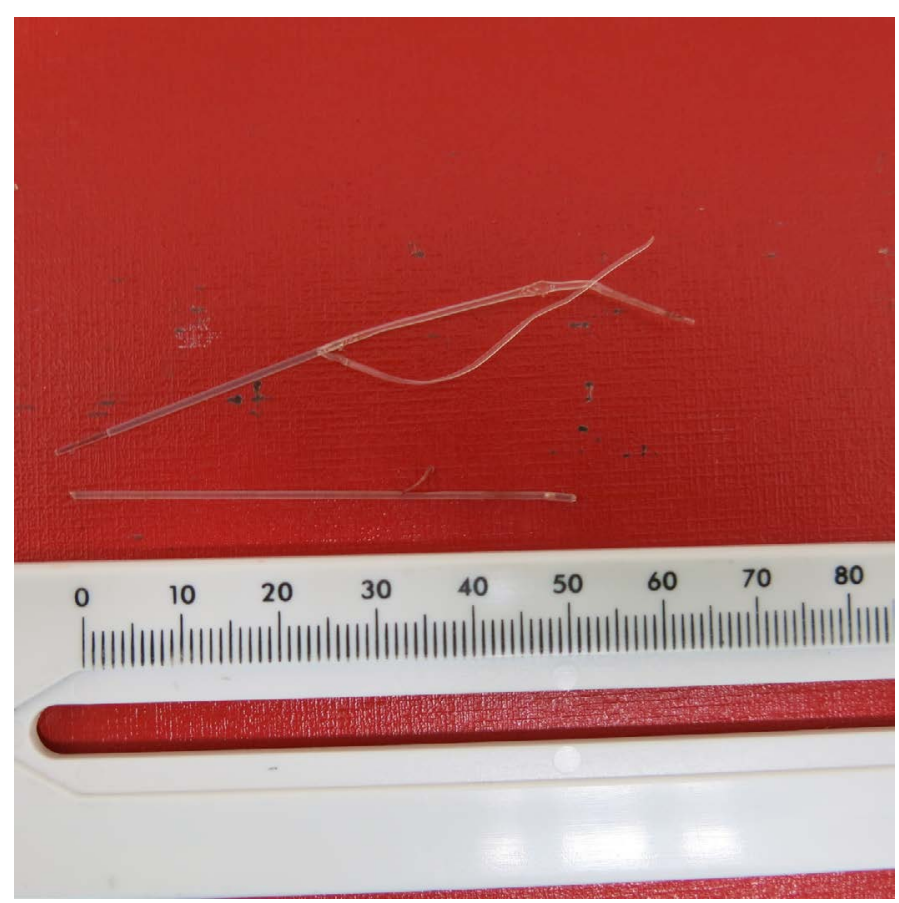

Figure 2. Retains of protective cover sleeve (no fiber!) from the bare fiber after surgical removal.

Table 1. Possible complications of laser lipolysis.

\begin{tabular}{|l|c|c|}
\hline \multicolumn{1}{|c|}{ Complication } & Frequency & References \\
\hline Mild temporary hyperpigmentation & $3.30 \%$ & {$[16]$} \\
\hline Hematoma and burns & $0.7 \%-2.5 \%$ & {$[9,17,18]$} \\
\hline Over- or under correction & $1.00 \%$ & {$[20]$} \\
\hline Local infections & $0.20 \%$ & {$[9]$} \\
\hline
\end{tabular}

accumulation of heat, melting of the protective coating fracture of the fiber [13].

\section{The present case}

In the present case, tumescent anesthesia was performed and completed before laser lipolysis.

No retained fiber was observed in the present patient but cover sleeve. Ultrasound investigations were negative for opaque retains. We discussed possible circumstances leading to this unexpected event. There was no carbonization visible at both ends of the surgically removed pieces. This makes the mechanisms discussed for fiber retains unlikely in our case. Bending of the fiber would have led to melting of the cover sleeve [13].

The cumulative energy for $980 \mathrm{~nm}$ laser lipolysis of the knee has been estimated as $8,100 \mathrm{~J}$ [14]. The cumulative energy that was employed in the present case was about half of this. This argues against unusual laser parameters during the procedure.

Since the tip of the bare fiber becomes covered by carbonized tissue during interstitial laser therapy [15], the tip has to be cut off repeatedly. For this purpose, the fiber is pulled out of the $17 \mathrm{G}$ coaxial needle and thereafter reinserted. During this procedure, the cover sleeve may have been unintentionally and unrecognized become damaged leading to severance. But if a puncture with a $21 \mathrm{G}$ needle damages the protective coating in as much as laser light leads to thermal peaks melting the coating [13], why did we not observe a similar thermal damage in the present case?

Despite all unanswered questions, a practical consequence of our observation is the need of routinely check of laser fibers after laser lipolysis.

\section{References}

1. Apfelberg D (1992) Laser-assisted liposuction may benefit surgeons, patients. Clin Laser Mon 10: 193-194. [Crossref]

2. Goldman A, Schavelzon DE, Blugerman GS (2002) Laser lipolysis: liposuction using Nd:YAG laser. Rev Soc Bras Cir Plast 17: 17-26.

3. Goldman A, Gotkin RH, Wollina U (2010) The evolution of laser lipolysis - 10 years of experience. Cosmoderm XVI - European Society for Cosmetic and Aesthetic Dermatology (ESCASD), Dresden (Germany), December 9-12, 2010. Medimond: Pianoro/ Italy 2011: pp. 21-6.

4. Goldman A, Wollina U, de Mundstock EC (2011) Evaluation of Tissue Tightening by the SubdermalNd: YAG Laser-Assisted Liposuction Versus Liposuction Alone. J Cutan Aesthet Surg 4: 122-128. [Crossref]

5. McBean JC, Katz BE (2011) Laser lipolysis: an update. J Clin Aesthet Dermatol 4: 25-34. [Crossref]

6. Valizadeh N, Jalaly NY, Zarghampour M, Barikbin B, Haghighatkhah HR (2016) Evaluation of safety and efficacy of $980-\mathrm{nm}$ diode laser-assisted lipolysis versus traditional liposuction for submental rejuvenation: A randomized clinical trial. $J$ Cosmet Laser Ther 18: 41-45. [Crossref]

7. Dudelzak J, Hussain M, Goldberg DJ (2009) Laser lipolysis of the arm, with and without suction aspiration: clinical and histologic changes. J Cosmet Laser Ther 11: 70-73. [Crossref]

8. Wollina U, Heinig B (2012) Tumescentmicrocannular (laser-assisted) liposuction in painful lipedema. Eur J Aesthet Med Dermatol 2(2): 56-69.

9. Katz B, McBean J (2008) Laser-assisted lipolysis: a report on complications. J Cosmet Laser Ther 10: 231-233. [Crossref]

10. Scurr JRI, Martin J, How TV, Gambardella I, Brennan JA (2006) Retained laser fibre following endovenous laser ablation. EJVES Extra 13: 30-32.

11. Lekich C, Hannah P (2014) Retained laser fibre: insights and management. Phlebology 29: 318-324. [Crossref] 
12. Ren S, Liu P, Wang W, Yang Y (2012) Retained foreign body after laser ablation. Int Surg 97: 293-295. [Crossref]

13. Holdstock JM, Marsh P, Whiteley MS, Price BA (2008) It is possible to cause damage to a laser fibre during delivery of tumescent anaesthesia for endovenous laser ablation (EVLA). Eur J Vasc Endovasc Surg 36: 473-476. [Crossref]

14. Reynaud JP, Skibinski M, Wassmer B, Rochon P, Mordon S (2009) Lipolysis using a 980-nm diode laser: a retrospective analysis of 534 procedures. Aesthetic Plast Surg 33: 28-36. [Crossref]

15. Amzayyb M, van den Bos RR, Kodach VM, de Bruin DM, Nijsten T, et al. (2010) Carbonized blood deposited on fibres during 810, 940 and 1,470 $\mathrm{nm}$ endovenous laser ablation: thickness and absorption by optical coherence tomography. Lasers Med Sci 25: 439-447. [Crossref]
16. Moreno-Moraga J, Trelles MA, Mordon S, Unglaub F, Bravo E, et al. (2012) Laserassisted lipolysis for knee remodelling: a prospective study in 30 patients. $J$ Cosmet Laser Ther 14: 59-66. [Crossref]

17. Chia CT, Theodorou SJ (2012) 1,000 consecutive cases of laser-assisted liposuction and suction-assisted lipectomy managed with local anesthesia. Aesthetic Plast Surg 36: 795-802. [Crossref]

18. Woodhall KE, Saluja R, Khoury J, Goldman MP (2009) A comparison of three separate clinical studies evaluating the safety and efficacy of laser-assisted lipolysis using 1,064 , $1,320 \mathrm{~nm}$, and a combined 1,064/1,320 nm multiplex device. Lasers Surg Med 41 774-778. [Crossref]

19. Holcomb JD, Turk J, Baek SJ, Rousso DE (2011) Laser-assisted facial contouring using a thermally confined 1444-nm Nd-YAG laser: a new paradigm for facial sculpting and rejuvenation. Facial Plast Surg 27: 315-330. [Crossref]

Copyright: $@ 02016$ Wollina U. This is an open-access article distributed under the terms of the Creative Commons Attribution License, which permits unrestricted use, distribution, and reproduction in any medium, provided the original author and source are credited. 